\title{
Koolielu kajastamine õpilaste omaloodud meemilehtedel kolmes Tartu piirkonna koolis ${ }^{1}$
}

\author{
Mare Kalda \\ Eesti Kirjandusmuuseumi folkloristika osakonna vanemteadur \\ kalda@folklore.ee \\ Astrid Tuisk \\ Eesti Kirjandusmuuseumi Eesti Rahvaluule arhiivi teadur \\ astrid@folklore.ee
}

Teesid: Artiklis keskendume Tartu piirkonna koolinoorte meemiloomingule, mida tavapäraselt postitatakse sotsiaalmeedias (spetsiaalsel Facebooki või Instagrammi lehel). Vaatlus põhineb koolide meemilehtede jälgimisel internetietnograafilise meetodiga ning intervjuudel meemide genereerijatega. Konkreetsete koolide igapäevategevusest lähtuvad meemid kajastavad ja peegeldavad meemide kui nüüdisaegse internetisuhtluse žanri kaudu koolielu, või nagu defineerivad ühe meemilehe pidajad, seavad ülesandeks olla "Peaaegu adekvaatne pilguheit K. kooli ellu". Iga kooli meemidele jääb piisavalt tõlgendusvabadust.

Kasutatavate motiivide ja kujutiste poolest mitmekesist, kuid adressaadi poolest piiritletud meemiderühma vaatame kui noortekultuuri osa. Meemide loomiseks, nagu ka nende mõistmiseks, on vajalikud teatud oskused, kus negatiivse või positiivse hinnangu osaliseks saamisel avalduvad oma käitumisnormid ja oma loogika. Meemidega tegeledes rakendavad koolinoored kultuurilist teadmist, meemikoodi, mida täiskasvanud ei pruugi mõista ja mis võib koguni üldse täiskasvanute vaateulatusest välja jääda. Mõne kooli meemilehtedel leiduvatest meemidest ei saa sageli aru ka teiste koolide õpilased, sest taotluslikult käsitletakse meemides oma kooli eluga seotud teemasid. Ühtlasi peegeldavad meemid tegijate endi väärtusi ning suhtumisi ümbritsevasse maailma ja inimestesse. Käesolevas artiklis toome valitud näidete põhjal esile koolielu kajastamise soovist tõukuvad populaarsed meemiteemad ja -motiivid nende sisulises ja vormilises väljenduses, mõistes noorte meemiloomingut kui digitaalse suhtlemise orgaanilist osa. Koolielu kohta loodud meemide toel teeme sissevaate sellesse, missuguseid eetilisi dilemmasid, konflikte ja konfliktide lahenduskatseid noored peavad vajalikuks meemide vahendusel esitleda, et pidada dialoogi nii oma meemikogukonnaga kui ka laiema identiteedirühmaga, kuhu nad kuuluvad.

Märksõnad: internetimeemid, koolifolkloor, lastefolkloor, noortekultuur, virtuaalkultuur 
"Meeme suht ausalt ei saa selgitada inimestele, kes on üle 30aastased." Memeoloogia Instituut videointervjuus Delfi TV-le (vt Kes teevad meeme? 2018)

Internetimeemid on ilming, mille jälgimise vastu hakati uurijahuvi üles näitama alles 21. sajandi esimese kümnendi lõpus (Börzsei 2013: 3-9; Milner 2016: 3). Käimasoleva sajandi teise kümnendi algusaastail ilmunud uurimustesse on autorid mahutanud muuhulgas ka oma kimbatuse, kuidas nende poolt avastatud uurimisobjektist poldud senimaani kuuldud või ei peetud seda analüütilist tähelepanu väärivaks ei meedia- ega kommunikatsiooniuuringutes, samuti mitte kultuurikirjelduses. Uue digitaalse kommunikatsiooni žanri tormilisele levikule rahvalikus internetis (rahvalikust internetist vt nt Howard 2008, 2012) reageerisid peagi kultuuriuurijad, kes tundsid internetimeemides ära analüüsi vääriva objekti - sellisest folkloorist ei olnud enam võimalik mööda minna, meemid vaatasid vastu põhimõtteliselt igalt poolt digitaalse maailma - eelkõige sotsiaalmeedia - avarustest. Nüüdseks on vaatlejad uudishimulikult tunginud isegi kõige metsikumatesse, kõige anonüümsematesse, peaaegu reegliteta keskkondadesse, et innuka osalusvaatluse toel kirjeldada ja kuidagi kategoriseerida sealset stiihiat ja sisuvooge (nt Mitchell 2013 4chani kohta). Samuti on meemide ja meemidega haakuva digitaalse suhtlemise vaatluses heaks tooniks refereerida Richard Dawkinsi meemi-mõistet, st arusaama kultuuriliste elementide ja ideede levimisest kopeerimise ja imiteerimise teel (McNeill 2009; Davison 2012: 120-123; Shifman 2013: 9-11, 16-17, 36 jj; Milner 2016: 12-21; Laineste \& Voolaid 2016: 27).

Internetimeemide analüütikud otsivad oma käsitlustes eelkõige kirjeldusviise, mis haaraks kogu žanri - sel juhul defineeritakse meeme kui digitaalse (igapäeva)suhtlemise viisi, internetimeemides nähakse sotsiaalmeedias suhtlemise ühiskeelt (eriti Milner 2016: 79-95). Folkloristid rõhutavad muude iseloomulike tunnuste hulgas just asjaolu, et internetimeemid kujutavad endast digitaalselt loodud (sündinud) ning digitaalse jagamise teel levivat folkloori (internetifolkloori mõistega tähistatav aines ei tähenda tingimata, et tegu oleks digitaalselt loodud sisuga). Digitaalselt leviva folkloori puhul on selgelt tunnuslik selle suutlikkus levida väga kiiresti ning mitte väga hoolida riigi- ega kultuuripiiridest. Niisuguste, iseenesest paikapidavate tõdemuste kõrval on oluline säilitada arusaam nii uuritavate formaatide kui funktsioonide mitmekesisusest, samuti ei ole ka iga konkreetse meemi(tüübi) evolutsioon ja leviku ulatus kaugeltki ühesugune. Tuntumate meemide "eluavalduste" vaatlemisel on abiks kasutajaskonna omapoolne liigitav ning jäädvustav tegevus: keskkonnas 
Know Your Meme on leitavad meemide arengulood koos aktiivsusgraafikutega, sageli ühe või teise meemi internetti ilmumise algusest peale. Viidatakse isegi vastavat meemi inspireerinud interneti-eelse ajastu tekstidele. Tegu on põhimõtteliselt kasutajaskonna enda initsiatiivil areneva ning täieneva meemientsüklopeediaga, näitega "pärimuskollektiivi emantsipatsioonist" tasandile, millel kasutajaskond ise arhiveerib ning uurib oma traditsiooni (vrd Honko 1998: 60). Keskkonda kuuluvates foorumites arutletakse ligilähedaselt samade meeme puudutavate küsimuste üle, mida erinevate valdkondade uurijadki püstitavad meedia- ja kommunikatsiooniteooria, folkloristika, lingvistika, visuaalkultuuri, semiootika või psühholoogia vaatepunktist - missugustest elementidest meem on kokku pandud, mis on meemi mõte, miks meem levib ja mis sellega levides toimub. Teiselt poolt aga kohtame meeme koondavatel kasutajate endi poolt sisuga täidetavatel saitidel väiteid, mida tuleb ette ka meemivaatajate hinnangutes ning intervjuudes meemimeistritega: meemid polegi mõeldud põhjalikuks seletamiseks ja kirjeldamiseks, vaid kiireks tarbimiseks ja edasisaatmiseks. Sellised keskkonnad nagu Know Your Meme osutuvad omakorda potentsiaalse uurimise objektiks (nt Kaplan 2013: 136-141).

Rahvaliku interneti puhul üldiselt räägitakse anonüümsusest - ja seda ka meemide puhul; meemide loojad jäävad anonüümseks, naudivad anonüümsusega saavutatud vabadust ega pretendeeri oma loominguga autorsusele (Davison 2012: 132-133). Käesolev artikkel keskendub võrdlemisi selgelt piiritletavale ainesele - käsitlemisel on koolielu kajastavad ja koolielust tõukuvad meemid. Nagu allpool näha ongi, tunnetasid meemide tegijad küsimuse olemasolu ning anonüümsuse hoidmine/mittehoidmine mõjutas nende tegevust ja valikuid. Väiksemas meemide kasutajaskonnas ei jää tegijad sageli anonüümseks, vaid siseringis teatakse, kes millise kasutajanime taga peitub. Tegelikult on ka edasijagamiste puhul ilmne, et teatud ulatuses ju tuntakse neid, kellelt edasisaadetav meem on saadud, samuti neid, kellele meemi omakorda jagatakse. Eesti kontekstis teatakse paljusid meemimeistreid. Näiteks motos viidatud videointervjuus esineb üks Eesti meemiloojatest, kes tänu nimetatud klipile kogus laiemat tuntust. Seevastu teine intervjueeritud meemitegijate tiim, kes esindas "Memeoloogia Instituuti", oma isikuid avaldada ei tahtnud, kuid nähtavasti suudab osa kommenteerijaist selle liikmeid identifitseerida. Videole järgnenud kommentaarides viidatakse meemitegijale flyingkitty, keda kommenteerijate arvates oleks tulnud kutsuda meemidest rääkima. ${ }^{2}$ Niisiis: meemidega toimetamine ei tähenda tingimata anonüümset osalemist. Asjaolu, et siinkirjutajad ning tõenäoliselt nii mõnedki lugejad ei tea, kes on flyingkitty, ei tähenda, et tema isik on sama anonüümne tema meemide nautijate ja edasisaatjate seas. Samas võib meemimeistrite anonüümsus olla mäng, mida kogukond kaasa mängib. 
Suurel meemimaastikul ringi vaadates tuleb muidugi teadlik olla meemide subkultuurilisusest. Limor Shifman räägib meemialasest kirjaoskusest (meme literacy, Shifman 2013: 113, 128-129) - erinevad meemiliigid eeldavad erineva tasemega meemi-kirjaoskust - ühtesid suudavad mõista ja luua peaaegu kõik inimesed, teiste mõistmine nõuab meemi-subkultuuri korralikku tundmist (samas: 113). Küsimuseks jääb siinkohal, kes moodustab subkultuuri? Kas noored meemikasutajad ongi subkultuur, kasvõi üksnes selles mõttes, et nad tunnevad meemikonventsioone ja oskavad meeme "lugeda" (ja luua), nad on asja(de)sse pühendatud, neil on ühised teadmised ja sümbolid ning nendest arusaamine? Konkreetsemalt lähenedes võiks subkultuurina määratleda teatud serverite või keskkondade ümber koondunud kasutajaskonda - kuna nemad on teadlikud seal kehtivate märkide-sümbolite tähendustest, mida nad suudavad dešifreerida (ja subkultuurivälised ei suuda). Limor Shifmani toodud loetelud meemidepõhised subkultuurid, kes on seotud lehekülgedega 4chan, Tumblr ja Reddit, näivad seda kinnitavat (Shifman 2013: 131). Subkultuure eritledes on uurijad esile toonud subkultuurilise kapitali mõiste (Thornton 1995; Allaste 2013: 45-46), mis teatud mööndustega kohaldub meemikultuurile - meemid võivad olla subkultuuriliseks kapitaliks. Meemimaailm on võrreldav klubiga, st ruumiga, kus kehtivad oma seadused, kus teotsemiseks on vajalikud teatud oskused, kus rakenduvad oma käitumisnormid ja loogika negatiivse või positiivse hinnangu osaliseks saamisel. Airi-Alina Allaste on sama meelt Sarah Thorntoni ilmselt paikapidava seisukohaga, et kui subkultuurilise kapitali elemendid võetakse (meedia vahendusel) peavoolu, siis nad kaotavad oma endise väärtuse $^{3}$ (Allaste 2013: 46). Midagi sellist on toimumas grafitiga. Koolimeeme kindlasti ei ähvarda autentsuse kadu ega väärtuse minetamine, sest et need ei saa peavoolu laia leviku osaks.

Niisiis paljude tegurite toel on põhjust pidada meeme noortekultuuri kuuluvaks ilminguks (mis siiski ei välista vanemate täiskasvanute meemide olemasolu, eriti rahvapärases poliitdiskursuses). Laste- ja noortefolkloor, olles osa lastevahelisest suhtlusest, elab ja seda jagatakse omavahel iseloomulikes, eri alustelt moodustunud eakaaslaste rühmades (Virtanen 1978; Tucker 2008: $20)^{4}$. Samas ei eksisteeri lastepärimus (kui lastekultuuri osa) täiskasvanute omast eraldi, vaid lapsed osalevad kahes - enda ja täiskasvanute kultuuris korraga, ning need kaks kultuuri on omavahel tihedalt põimunud (Corsaro 2009: 301-315). Osalust, omaloomingulisust ja omavahelise suhtluse taotlust on laste ja noorte internetipärimust uurides välja toonud ka Eesti uurijad (Kalmre 2015; Voolaid 2014).

Endiselt on jõus iseloomustus, mille Eda Kalmre andis aastate eest laste- ja noortepärimusele (Kalmre 2005: 165-166). Parafraseerides tema toonast mõttekäiku laste- ja noortepärimuse vastukultuurilisest iseloomust selgub, et ka 
meemide kaudu toimub kellegi ninapidivedamine, ületrumpamine, väljavihastamine, narritamine, tabuteemadest rääkimine, võimalus samaga vastata ning olla nupukas ja taiplik, isegi ennast arendada. Ka meemides on kehastunud kasvuraskused, tunded, hirmud, isiklikud ja ühised probleemid, arutluse all on täiskasvanute maailma väärtushinnangud, mis läbivad noortepoolse tähelepaneliku hindamise vooru. Noorte meemiloojate poolt välja pakutud hinnanguid ja tõlgendusi ilmestab sageli absurd ja huumor. Kuid huumor pole siiski ainuvaldav tundekategooria: kui mõned autorid defineerivad meeme huumori võtmes, ei ole meemid kaugeltki iga kord mõeldud naljaks, nende ainult naljažanriks defineerijal jääb midagi märkamata.

\section{Meemide kui noortekultuuri osa kogumise ja tõlgendamise metoodikast: koostöö kasutajaskonnaga}

Käesolev ülevaade seab vaatluse keskmesse koolielu peegeldavad ja tõlgendavad meemid niisugustena, nagu meemitegijad on need netikeskkondadesse üles laadinud. Kasutatavate motiivide ja kujutiste poolest mitmekesist, kuid adressaatide poolest piiritletud meemiderühma mõistame kui noortekultuuri osa. Noortekultuuri uurija Rebecca Goldstein postuleerib täiskasvanud uurija positsiooni nii: tuleb ise kõnelemise asemel kuulata, mida noortel on öelda, taipamaks seda, millest nad räägivad, mida mõtlevad ja tunnevad. Kuulamine, ka noortemuusika kuulamine annab sissevaate sellesse, mis on noortele oluline (Goldstein 2006: 10). Meie kuulame vaadates - keskendume meemidele, mis esitavad reportaaže valitud koolide argipäevast, kuhu lõikuvad mõned vähem argised sündmused. Oleme seda teinud viimase kolme aasta jooksul koostöös oma noorte informantidega, kümneliikmelise ekspertide rühmaga (vanuses 16-25), tänu kellele oleme pühendatud asjadesse, mis muidu oleks jäänud märkamata.

Lähenemismeetodina rakendame internetietnograafiat, mis eeldab aktiivset kohalolu uuritavas keskkonnas ehk siis kaksikrolli täitmist: tegutsemist isikuna ja etnograafina (Hine 2015). Uurija on sotsiaalmeedias kohal kui inimene (nii nagu teised sama keskkonna tavakasutajad, kes osutuvad sel kombel uurimispartneriteks), ent samal ajal teeb ta oma eriala nõuetest tulenevaid tähelepanekuid, kogub uurimisallikaid (näiteks salvestab meeme). Oleme alates 2017. aastast regulaarselt jälginud meemide liiklust oma isiklikes uudisevoogudes erinevatel sotsiaalmeedia platvormidel. Kuna meil on sotsiaalmeedias koolinoortest "sõpru", siis satub koolinoorte meeme meie kui tavakasutajate vaateulatusse ka ilma etnograafi rolli minekuta. Enamasti jagavad teismelised meeme omavahel, olles osavate internetikasutajatena seadnud piiranguid 
isikute kohta, kes nende postitusi näevad. Sellegi poolest on meil teatud määral teadmist, missuguseid mitte-koolielu meeme noored sotsiaalmeedias oma seinale postitavad - see on võimalik, kuna meie etnograafidena (täpsemalt folkloristidena) kasutame sama meediat kui meie uuritav "meemikogukond" (vrd Hine 2015: 81-82). Allpool vaadeldavad meemid on enamasti avalikult kättesaadavad, ent meemide tõlgendamiseks, neist arusaamiseks on intervjuud koolimeemide autoritega hädavajalikud.

Keskendume peamiselt kolme põhikooli meemilehe vaatlusele, võrdlevaid näiteid toome ka teiste koolide meemilehtedelt.

(0) Instagram

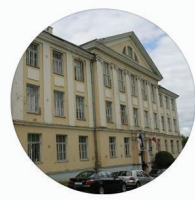

(0) Instagram

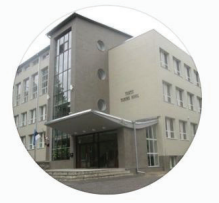

\section{karlovameemid Following $•$ - .}

102 posts $\quad 456$ followers $\quad 2$ following

Karlova meemid

peaaegu adekvaatne pilguheit Karlova Kooli igapäevaellu

Kui käid Karlovas ja sul on meeme, saada meile directi. Autori tagime meemi alla.

Joonis 1. Karlova meemide esileht.

a Search

(2) $0 \stackrel{\circ}{\circ}$

\section{tammemeemid Follow - ... \\ 62 posts $\quad 436$ followers $\quad 3$ following \\ Tamme meemid \\ vaade Tamme Kooli igapäevaelu kaadritagustesse \\ kui sul on *PõLEVAID* meeme, libise dm'idesse for krediit garanteeritud! \\ www.tamme.tartu.ee}

Joonis 2. Tamme meemide esileht.

(0) Instagram

(2) $0 \circ$

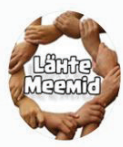

lyg_meemid Follow -...

82 posts 457 followers 2 following

Lăhte meemid Toûpiline meelelahutusleht Lăhte ÜG sũdamest $\odot$ Saada enda pildid

directi, kredit garanteeritud $\circledast$

Followed by karlorameemid

Joonis 3. Lähte meemide esileht. 
Karlova Kooli meemilehel leidub 102 postitust ajavahemikus 20. maist 2017 kuni 3. juunini 2018. 2019. aasta seisuga Karlova meeme juurde ei looda, sest lehekülje tegijad lõpetasid kooli ning nende huvi meemilehe tegemise vastu vaibus. Tamme Kooli meemilehel leidub 61 postitust, esimene neist kuupäevaga 16. august 2017, viimane 31. jaanuaril 2019. Ka Tamme leht enam ei täiene. Kolmandaks oleme valinud Tartu maakonnas asuva Lähte gümnaasiumi, mille meemilehe autorid olid samuti põhikooliealised. Tõenäoliselt on nende meemide aktiivsed kasutajad - laikijad, kommenteerijad ning edasijagajadki pigem põhikooliealised. Lähte meemileht on oma populaarsuselt ja suunitluselt võrreldav linnakoolide meemilehtedega. Esimene Lähte meem postitati 14. detsembril 2017 ning seal leidub 82 postitust. Lähte meemilehe tegijad jätkavad lehe täiendamist.

Tartus on kokku 27 põhiharidust andvat kooli. Teadaolevalt peavad või pidasid meemilehte siinsetest põhikoolidest veel Tartu Hansa Kool ("Hansa meemid", sisu pärineb ajavahemikust 17. oktoober 2017 kuni 23. jaanuar 2019) ja Forseliuse Kool ("Forsa meemid", postitused ajavahemikust jaanuar 2017 kuni mai 2018). Need lehed ei ole nii populaarsed kui kolm eespool nimetatut, ka meemide hulk kummalgi lehel on väiksem. Kas Tartu koolide meemilehti oli 2017/2018 rohkem, vajab veel täpsustamist. Facebookis leiduvad "Kivilinna meemid", MRK (Tartu Mart Reiniku Kooli) meemid ja Raatuse meemid ei ole avalikult nähtavad, nad on kas kustutatud või pole olnudki aktiivsed, samuti "Raatuse miimid" Instagrammis. Meemilehti tehakse lähtuvalt autorite initsiatiivikusest pidevalt juurde, nii alustas 2018. aastal Instagrammis MRK meemileht, kuhu tänaseni meeme postitatakse. Jätkuvalt populaarsed on Tartu kahe prestiižsemaks peetava gümnaasiumi, Hugo Treffneri gümnaasiumi ja Miina Härma gümnaasiumi meemilehed.

Käesolevas vaatluses piirdume kolme esimesena nimetatud lehega. Karlova, Tamme ja Lähte koolide meemilehtede tegijad olid üksteise olemasolust teadlikud ning lehed olid seatud üksteise jälgimise režiimi. See asjaolu - meemilehtede omavaheline "dialoog" ajendas meid kolme kooli meemide lehekülgi omavahel võrdlema. Kõik kolm saiti kasutasid Instagrammi platvormi. Meie põhiline vaatlev kohalolu toimus kuni 2018. aasta mai lõpuni.

Koolide meemilehtedel on mitmeid vormilisi sarnasusi ja kujundusvõtteid, selgelt rõhutatakse (profiilipildi abil) seotust kooliga. Tamme ja Karlova meemide "kaanepildiks" on koolimaja kujutis. Lähte lehel näeb vaataja ühendatud kätest ringi, mille keskel pealkiri: Lähte meemid. Samuti presenteeritakse meemilehti omaloodud tunnuslausega. Tegijad on intuitiivselt tabanud, et nagu äritegevuses aitab tunnuslause kliendiga paremat kontakti saada ja kasvatab tuntust, nii toob nende unikaalne juhtlause esile kasutajate arvates ilmekaima koolimeemide peaidee, ja kutsub vaatama. On ootuspärane, et tunnuslause 
rõhutab seost kooli igapäevaeluga ja leht on siis vastavalt mõeldud kajastama kooli siseelu. Sõnavalikuga kriipsutatakse alla seda, et tegijad on koolielu tõelised tundjad, kursis ka sellega, mis toimub kaadri taga. Lähte tunnuslause kinnitab, et leht tuleb otse koolielu südamest: "Tüüpiline meelelahutusleht Lähte ÜG südamest”. Tamme ja Karlova koolilehtede tunnuslausetes tõstetakse esile seost kooli igapäevaeluga: "An almost adequate glimpse at the everyday life in the Karlova school" ja "Vaade Tamme Kooli igapäevaelu kaadritagustesse". Maikuus 2019 on Lähte meemilehe tunnusfraas muutunud: ennast tutvustatakse kui meelelahutuslehte Lähte Ühisgümnaasiumist.

Meemilehtede tegijate isikud jäävad juhukülastajale kõigi kolme kooli puhul pigem varjatuks. Siiski on lehele sattujale selge, et tegijad on sama kooli õpilaste hulgast. Lehed on valdavalt avatud suhtlemiseks, kuid meeme saavad kommenteerida ja neile emotikonidega reageerida ainult jälgijad. Rakendub osalusmeedia omadus: vaatajaid kutsutakse mitte ainult kommenteerima ja laikima, vaid ka ise meeme genereerima ja neid lehetegijatele avaldamiseks saatma. Meemikogukonnad on ka aktiivselt üleskutsetele reageerinud - lehtedelt leiab mitmeid vaatajate saadetud meeme. Saatjad "saavad selle eest krediiti", nende nimi märgitakse meemi juures ära.

\section{Tegijate vaade - intervjuu meemilehe tegijatega}

Käesolevas kontekstis huvitas meid, missugune on tegijate endi vaade oma tegevusele koolimeemide loojatena, selle teadasaamiseks viisime läbi intervjuu ühe kooli meemilehe autoritega. Intervjuu läbiviimist kergendas usalduslik suhe noorte autoritega. Et mitte kahjustada tegijate ega koolide huve, jätame märkimata, missuguse kooli meemilehe tegijatega me rääkisime. Järgnevalt tutvustame noorte vastustele toetudes, mis käivitas meemiloome, mis noori motiveerib ja kuidas tegijad ise hindavad oma tegevust.

Meemide lehekülge [A] peavad kaks tüdrukut, Mona ja Helin (tüdrukute nimed muudetud), kes mõlemad on sündinud 2002. aastal, nad on intervjuu tegemise ajal 16aastased ja õpivad 9. klassis.

Neiud on klassikaaslased ja sõbrad. Mõlemad on agarad internetikasutajad, kes aktiivselt navigeerivad neid huvitavatel saitidel. 2013. aastal tehti koos Facebooki-lehte "Rihanna jutukas" (nimi muudetud), mis kujutas kahe sõbranna, Shaki ja Shaku elusündmusi. Leht toimis aastatel 2013-2014 ja selles ilmus üheksa pala. Kooli meemilehe tegemise mõte tuli spontaanselt ja läks liikvele asjaolust, et kooliga seotu oli neidudel omavahel sagedane jututeema. Helin viib kokku kaks poolt: neile kui sõbrannadele nagunii meeldis nalja visata kooli ja koolielu üle, samas olid erinevad meemilehed väga populaarsed, nii et 
nad mõtlesid: miks mitte teha üks ka oma koolile. Nii on kooli meemileht jätk tüdrukute muudele tegemistele sotsiaalmeedias.

Intervjuu puudutas ka küsimust, kui palju jälgijaid loodeti saada ning kas tegijate varjujäämine oli eesmärgiks. Helini sõnade järgi kujunes anonüümsus tegutsemise käigus: "Me ei arvanud alguses, et me väga palju üle 300 jälgija võiks saada. Alguses oligi plaanis enda nimed avaldada, kui meil on 200-300 jälgijat. Ent see arv sai päris ruttu täis. Seega otsustasime olla tundmatud seni, kuni [A] meeme aktiivsena suudame hoida."

Meemitegijate nimesid ei teadnud esialgu isegi klassikaaslased. See oleks võinud nii jääda, kui üks postitustest poleks vallandanud mõnevõrra ootamatut konflikti. Arusaamatuse tekitas ühe meemilehe jälgija saadetud foto, mis kujutas kooli spordipäeva. Foto pandi meemilehele välja, ent sellel selja tagant pildistatud õpilane tahtis foto eemaldamist leheküljelt ning pidas õigeks pöörduda kooli juhtkonna poole. Probleemi lahendamiseks asus direktsioon asja lähemalt uurima, ja direktorile üllatuseks selgus, et meemilehte peavad hea õppeedukusega ja kaaslaste suhtes igati heatahtlikult meelestatud tüdrukud. Mona ja Helin kutsuti direktori juurde selgitusi andma. Koolijuht oli seni olnud teadmatuses taolise meemitraditsiooni olemasolust ja harrastamisest tema juhitud õppeasutuses. Konflikti tõttu (või tänu konfliktile) pühendati Mona ja Helini kooli direktor koolimeemide loogikasse, ta oli väga mõistev ja mingeid sanktsioone ei järgnenud. Direktori ja tüdrukute vahel asju arutades kerkisid üles küsimused erinevast meemimõistmisest - täiskasvanud ja noored tõlgendavad sama kujutist erinevalt, ka huumoritunnetus on erinev. Tuli välja ka see, et täiskasvanud ei tunne noorte kasutatavat vormi ega sisu ning hindavad seda oma arusaamade kohaselt. Direktorit oli isiklikult kurvastanud, et meemis "Kui suvevaheajal tuleb meelde kool" oli nende oma kooli peetud ebameeldivaks kohaks. Tegemist oli diametraalselt erinevate tõlgendustega, kuna tegijad väljendasid meemiga vaid oma tundeid, et suvevaheaeg on toredam aeg kui igapäevane kooliskäimine.

Veel kirkam ja suuremat hulka inimesi haaranud meemikonflikt puhkes ühe teise koolimeemi tõttu. See ei ole küll seotud juhtumiga [A], ent piltlikustab väga ilmekalt, mis juhtub, kui meem satub tavalisest kasutuskontekstist välja, pannes vanemaid või muidu meemimaailmas kirjaoskamatuid inimesi, kaasa arvatud institutsioone, üle reageerima. Samas võib seegi - mitteteadjate häirimine - olla osa mängust. Maikuus 2018 lõid "memeoloogid” Facebooki ürituse "Laseme üheskoos mata eksami üle", mille toimumise kuupäevaks oli planeeritud 25. mai ("libaeventi" lehekülg on endiselt leitav, vt Mata eksam 2018). Nimetatud initsiatiivi kommentaari pakub üks meemitegija ka juba viidatud DelfiTV meemivideos: "Kõik võtavad seda liiga tõsiselt, vanemad inimesed." Tõepoolest, mitte kunagi toimuma pidanud ürituse korjas üles meedia 
ja asus häirekella helistama: noored kutsuvad üles riigieksamile mitte minema. Ametliku meedia protseduuride mõttes õigesti paluti kommentaari Gustav Adolfi Gümnaasiumi direktorilt ning eksamikeskuselt Innove. Ka Haridus- ja Teadusministeerium avaldas oma pöördumise (postitatud mitte kunagi toimuma pidanud sündmuse Facebooki seinale): "Hea koolilõpetaja - gümnaasiumi lõpetamiseks on Sul vaja sooritada kolm riigieksamit (eesti keel, võõrkeel ja matemaatika). Kui jätad mõnele eksamile mõjuva põhjuseta tulemata, siis ei ole võimalik ka paraku gümnaasiumit lõpetada, sest uuesti on võimalik riigieksamit teha alles järgmisel õppeaastal." Postitused samal lehel väljendavad väga huvitavaid reaktsioone, milles meemiloogikat rakendades mängitakse mitte kunagi toimuma pidanud sündmusega kaasa ja iroonitsetakse nende suhtes, kes valesti aru saavad. Ka kommentaarides leidub koolimeeme, muuhulgas otseselt matemaatika eksami sooritamise teemal. Tõsi, "mataeksami meem" erineb oluliselt eespool kirjeldatud juhtumist, kuna juhtumis [A] on tegu fotole jäänud kaasõpilase inimliku sooviga kontrollida, kus eksponeeritakse temast tehtud pilti.

Kui täiskasvanud ootaks, et meem oleks kuidagi lahti seletatud, siis meemide kasutajate vaatevinklist on see nonsenss. Sisuloojate sõnul (ja sama kinnitavad teised meemisubkultuuride kandjad) kaotaks meem lahtiseletatult oma löövuse. Meemides minnaksegi üle piiri.

Võimalikuks konfliktseks alaks koolimeemides on õpetajate ja teiste õpilaste kujutamine ning seeläbi tekkivate hinnangute ja kuvandi levitamine. Tüdrukute hallataval meemilehel oli alguses õpetajatest tegelastega meeme, kus neid nimetati nimepidi. Tüdrukute vanemad soovitasid need eemaldada. Õpetajate nimesid pigem välditakse ka teistel vaadeldavatel meemilehtedel. Tüdrukud räägivad ka ühest juhusest Tartu koolis, kus õpetajat kujutanud meemi pärast ähvardas selle tegijat koolist väljaviskamine. Üldiselt ei leidu vaadeldavatel koolide meemilehtedel taotluslikult solvavaid ega üliiroonilisi (dank) meeme. ${ }^{5}$ Meemilehekülgede haldajate valikul, kohati ka vanemate ja õpetajate nõuandel, ei kasutata siin enamasti ebatsensuurseid väljendeid ega lubata endale seksuaalse vmt alatooniga nalju, mis muidu on meemides levinud. Üsna kindlalt võib väita ka seda, et üks osa täiskasvanuid (nii õpetajaid kui ka lapsevanemaid) pole neist meemidest teadlikud, muidugi polegi need neile mõeldud. Õpetajatega seotud meemidest tuleb artiklis veel juttu.

Missugused on meemitegijate endi eelistused meemimaailmas? Osaliselt tähendab see küsimust meemimallide (template) rakendamise ja vabas vormis meemikujunduse vahekorrast. Tõenäoliselt on eelistused individuaalsed, ja meemide tohutu hulga juures on näha, et mõlemad kujundusviisid annavad ühtviisi uut ainest juurde. Intervjueeritud tüdrukute lemmikmeemideks on 
sellised, kus kas luuakse kogu meem nii sisus kui ka vormis uuena või kasutatakse küll olemasolevat malli, kuid rakendatakse seda loovalt. Mona sõnul meeldivad talle tööd, "millega näed natuke vaeva ka". Nii näiteks põhineb lehekülje kõige populaarsem meem "Reedene ühisvastamine läheb ikka vahel pikale" (237 meeldimist ehk laiki) reaalelu situatsioonis tehtud fotol, millel näeme valgustatud klassiaknaid. Mona oli kord koolist möödudes niisuguse pildi teinud, foto ja teadmine järelvastamistest inspireerisid teda meemiloomele. Meem oli mõeldud edastama lihtsalt tõdemust, et järelevastamine hilise ôhtutunnini on püsivalt probleemiks. Koolis kehtib teatavasti kord, et reedeti saab ühes klassiruumis teha või parandada tegematajäänud või ebaõnnestunud kontrolltöid ja tunnikontrolle.

Võrdlusena kujutab populaarseim Tamme meem sildiga 'Ajalugu' tähistatud lumeonni, mis illustreerib kooli ühe aineõpetaja taotlust õhutada klassiruumi ka kõige külmemate ilmadega (215 laiki).

Igas mõttes - nii sisus kui vormis - ise väljamõeldud ja teostatud meemid sünnivad puhtalt assotsiatsioonide pealt: mingi olukord või seisund meenutab mingit teist olukorda või seisundit. Näiteks meem "Kui koolis hakatakse Teist maailmasõda õpetama" sündis Mona sõnul ühisest joonisfilmi vaatamisest, kus filmitegelase Lotte poos meenutas veidi natslikku tervitust.

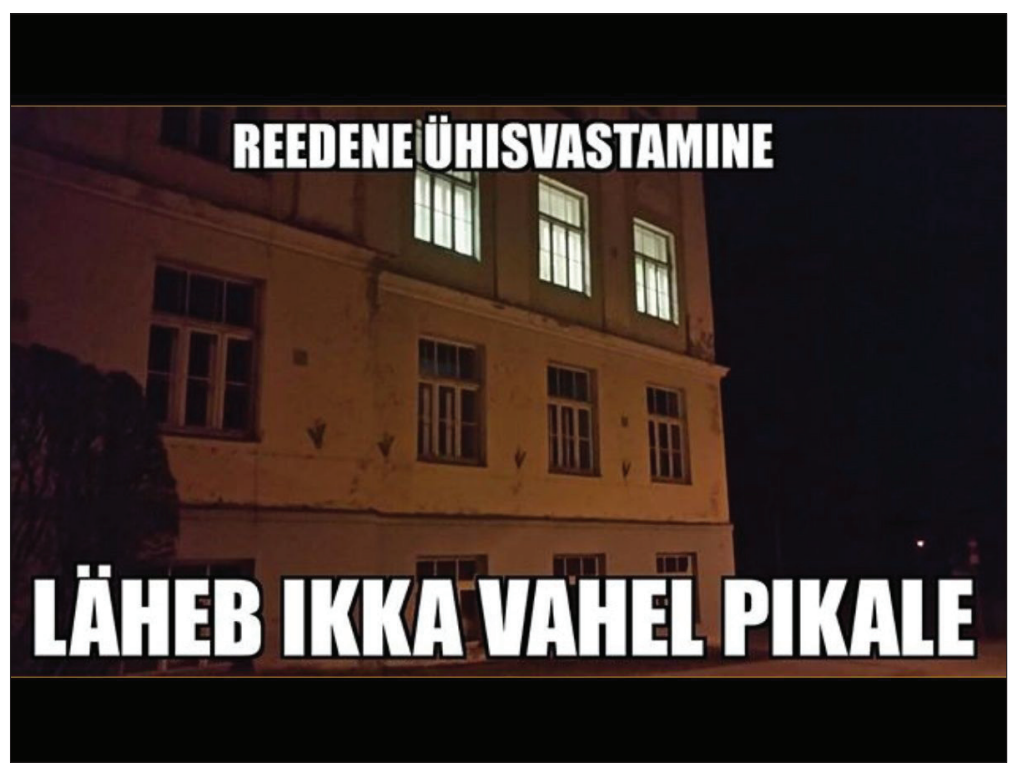

Joonis 4. "Reedene ühisvastamine läheb ikka vahel pikale". 


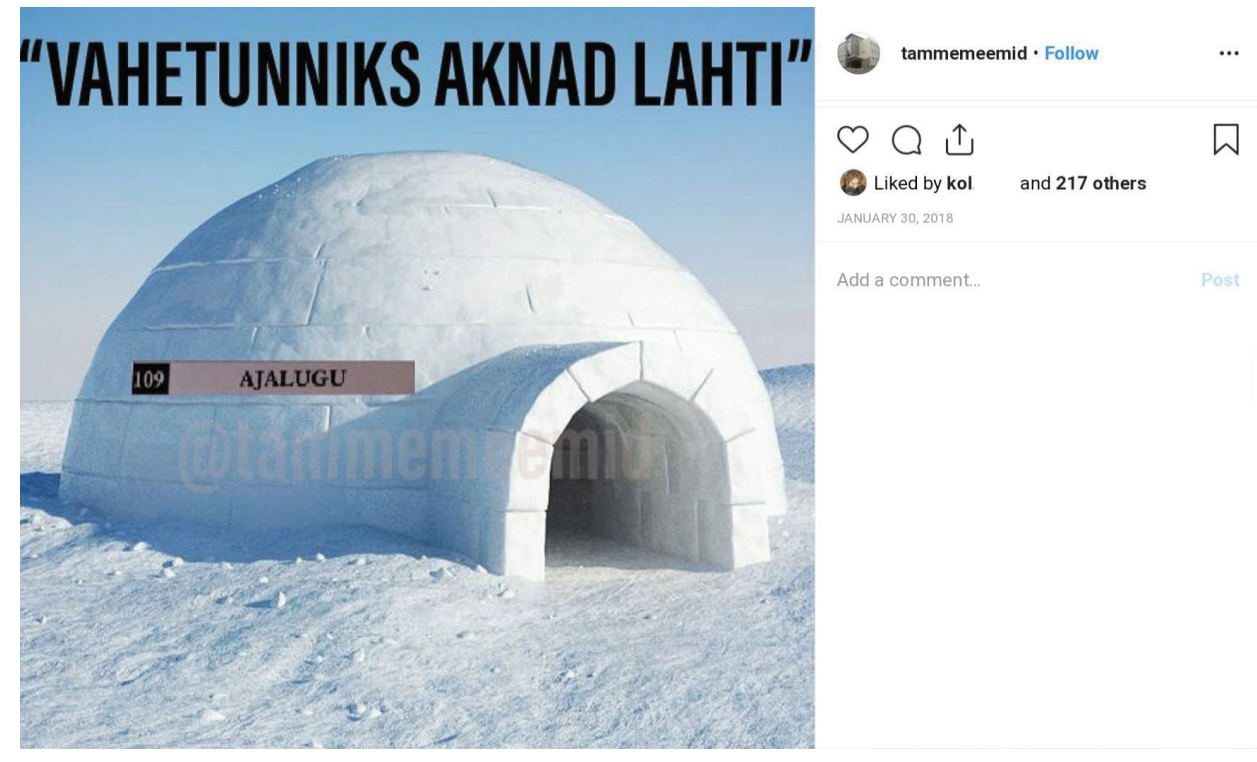

Joonis 5. Lumeonni meem.

Nagu meemide puhul tavaline, kubisevad ka vaadeldavad meemid intertekstuaalsetest vihjetest (Shifman 2013: 2-4; Laineste \& Voolaid 2016). Eelmises kontekstis esinenud pilt, lause või mõte tõstetakse uude konteksti, vana kas laenatakse iseendana või tehakse üksnes peen vihje. Noorte arvates pidi silt 'Ajalugu' lumeonni peal looma seose iga ilmaga maksimaalselt tuulutatud klassiruumi ja õpilaste külmatunde vahel. Nagu intertekstuaalsete viidete puhul võib juhtuda, on siingi vajalik "teksti" eelmise tähenduse tundmine, et vaatajatel seostuks see konkreetse õpetaja tuulutamissoovituste ja külmeneva klassiruumiga. Kes seda konteksti ei tea, sellele ei ütle meem suurt midagi.

Peale konkreetsete asjaolude teadmise eeldavad meemid nende kasutajatelt ka meemi vormivõtetega opereerimise oskust. Eespool on osutatud meemide kultuurilisele koodile või sümbolkeelele, mida nii meemitegijad kui meemide vaatajad-kommenteerijad ning edasisaatjad peavad tundma ja tunnevadki (vrd Shifman 2013: 128-129). Tehniliselt on meemide teokstegemine tänapäeval suhteliselt lihtne, valmisrakendused on saadaval ja neid kasutatakse. Noortel arvutikasutajatel on piisavalt oskusi ise meeme konstrueerida. Valmisformaate ning meemimalle kasutatakse muidugi ka, samuti rändab ühest meemist teise sisu: mitmesugused pildid, popkultuuri tegelased, millegi poolest noori köitvate kuulsuste isiksused jne, mida täiendatakse individuaalsete illustratsioonidega - 
siin väljendub meemide variatiivsus. Nii pole üllatav, et eri koolide meemisaitidel ja vahel ühe meemilehe piires korduvad samad kujundusmallid, mida kasutatakse ka teistes meemides, mujal noortekultuuris (või teistes kultuuripiirkondades). Üks osa kujundusmalle on üldtuntud, andmaks edasi teatud stereotüüpe (nt Albert Einsteini kujutamine seostub sageli tarkusega). On selge, et meemides saab originaalne olla vaid teatud piirini - mingist piirist üle minnes võib jääda meem mõistetamatuks ega pälvi jälgijate tunnustust. Teiselt poolt peab paika, et algupärane vaimukus, teravmeelsus on meemimaailmas väga hinnatud omadused. Reedese ühisvastamise meemi ning iglu-meemi järgi võiks arvata, et rohkelt laike saavad meemid, mille intertekstuaalne vihje töötab-meem haakub millegagi vastuvõtjate kogemuses. Tamme kooli uusimatest meemidest üks rohkema laikide arvuga on meem saatetekstiga "Kolmas maailmasõda". Viite taga on asjaolu, et Tamme meemilehe kõrvale on tekkinud uus või(s)tlev meemileht "Tamme memes", mis aga vanade tegijate arvates nende lehte lihtsalt kopeerib. Tekstiosa "Ma luban sul maha vaadata, aga muuda midagi, et õpetaja aru ei saaks" kõnealuses meemis on üks meemides korduv püsivormel. Tuttav koolitööga otseselt seotud lause on adresseeritud teise meemilehe tegijatele, millest tekib tore assotsiatsioon. Meemipublik (jälgijad) näib nautivat koomilises võtmes esitatud kahe meemilehe võitlust.

\section{„Ma luban sul maha vaadata, aga muuda midagi, et õpetaja aru ei saaks."}

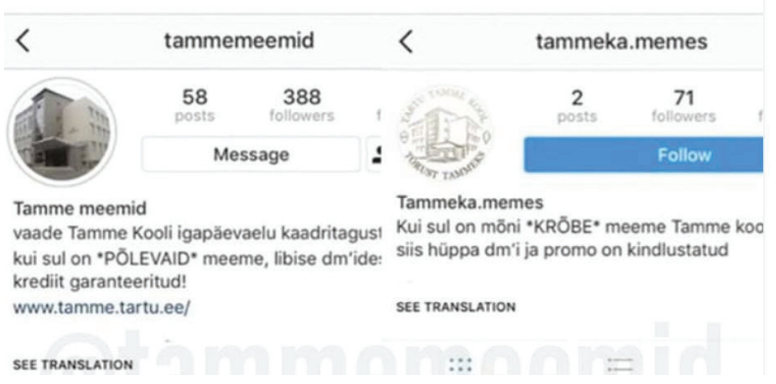

tammemeemid · Follow

tammemeemid III maailmasõda krediit >>@mete

$65 w$

(3) näha

65w 4 likes Reply

HAHAHAHAHAHAHAHAHHAHAHA HAHAHAHНАНАНАНАНАНАНА

Joonis 6. "Kolmas maailmasõda". 
Meemitegijate väljakutseks on niisiis leida sobiv vorm, millesse valada hea sisu, tähtis on leida meemikogukonda (või samasse identiteediringi) kuuluvaid kaaslasi kõnetav teema, kas sündmus, isik, situatsioon vms. Populaarse meemi tegemiseks ei piisa ainult meemikonventsioonide tundmisest. Kohalikus meemikogukonnas - antud juhul ühe kooli meemikajastuse ümber koondunud "pärimusrühmas" autoriteedi omandamiseks on vaja oma kooli eluga hästi kursis olla. Sama hästi tuleb tajuda noorte rühmakultuuri, tunnetada oma jälgijate ootusi ning suhtumisi, taluda nende vastukaja - siis on meemide populaarsus saavutatav. Robert Glenn Howard arutleb samas võtmes photoshop-meemide tegijate autoriteedi üle, leides, et populaarsed saadused sünnivad rohujuuretasandi loojatelt, kes tajuvad oma kogukonna ootusi (vrd Howard 2008: 194; üldisemalt ka Howard 2013). Nagu on tavapärane rahvaluulele pärimusrühmas, väljendavad meemid koolide meemisaitidel oma jälgijate suhtumisi. Kasutajate suhtumisi ja hoiakuid väljendavad nende reaktsioonid - laigid ja kommentaarid. Kuna jälgijaid on võrdlemisi palju (kõikidel viidatud meemilehtedel vähemalt 500), võib arvata, et nagu rahvaluuleprotsessides üldiselt, toimivad ka meemide puhul sellesse haaratud osaliste vastasmõjud (Valk 2005: 11) ja et ka meemid kujundavad vaatajate-kaasaelajate arvamusi ja hinnanguid.

\section{Kõnekaid detaile koolide meemilehtedel}

Heites pilgu koolimeemide temaatikale on võimalik eristada nii universaalsemaid meeme kui ka konkreetse kooliga seotud teemasid. Esimesed illustreerivad koolielu üldse, õppimisega seotud raskusi jms, teised seevastu eeldavad konkreetse kooli siseeluga kursis olekut, kaasa arvatud õpetajate tööstiil, kooliruumide "geograafia", kooli tähtpäevad. Kuigi kasutatakse valmisprogrammeeritud meemivorme või rakendusi, vahetatakse vajadusel välja detaile kas meemi pildi- või tekstiosas, et siduda meem oma kooli ja siin aset leidnud juhtumitega. On selge, et meemide autoriteks on antud koolide õpilased, kes on kursis kooli siseeluga õpilase perspektiivist. Seni toodud näited järelvastamise tõttu valgustatud akendega [A] juhtumi ning koolitunnist lumeonnis Tamme kooli näitel on just konkreetse kooli konkreetsete olude kajastused meemides.

Üheks meeme tegema ja jagama inspireerivaks teemaks on koolitoit ja koolisöökla. Söökla, toidu ja söömisega seotud meemidest on üks osa selliseid, mis käiksid justkui kõikide koolisööklate kohta. Näiteks aplodeeriv publik meemis, kus kellelgi midagi kukub ja puruneb või kolinat tekitab - teema leiab kasutamist mitme kooli meemides. Mõned koolitoiduga seotud teemad (ja nendega esitletud probleemid) korduvad eri koolide puhul, näitaks keeld sööklast puuvilju või leiba välja viia. Teatud määral väljendavad meemid rahulolematust 
Joonis 7. Tamme koolisöökla stardipakett.

\section{TAMME KOOLI SÖÖKLA}

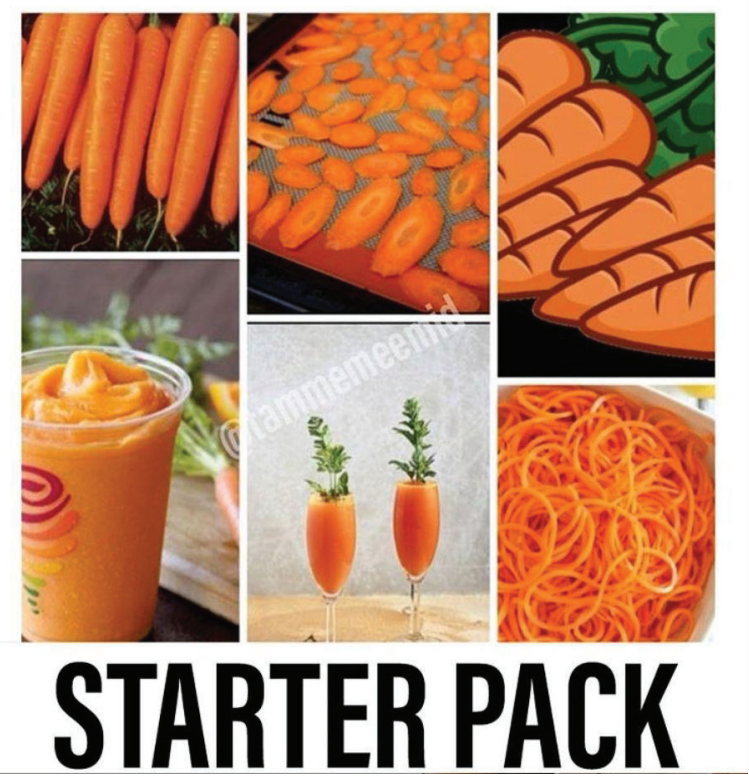

koolitoiduga (kahes näites esitletakse halva toiduna koorest kalasuppi). Koolitoidumeemides ei osutata siiski ainult probleemidele, vaid ka tugeva positiivse emotsiooni tekitajatele, üheks selliseks on näiteks meemid koorese kanapasta kiituseks.

Lisaks toidule käsitletakse meemivormis söömise korraldust, õpilaste ja õpetajate käitumist, halba lõhna sööklas vm. Isegi kui meemis kirjeldatakse konkreetset kooli, võiks meem samahästi kajastada ka teiste koolisööklate olusid. Näiteks meem "Tamme kooli söökla starter pack" ${ }^{\text {, }}$ kus söögikord koosneks justkui eri viisil serveeritud porganditest, annab ainet tõlgendusteks. Kas näeme siin viidet koolitoidu ühekülgsusele, tegijate sõpruskonna köögiviljapõlgusele või koguni ühiskonnas levitatavatele tervisliku toitumise soovitustele (mis sellisena absurdi viiakse) - kuidas keegi meemi mõtestab. Nii annab see teemablokk edasi õpilaste vaates kitsaskohti kooli toitlustuses. Koolisöökla ja -toiduga seotud meemid paigutuvad konkreetsesse aegruumi - 2000. aastate algusesse, kajastades sellele perioodile omast elu-olu. Sööklas on vabalt võetavad puuviljad ja näkileivad, eraldi road taimetoitlastele, samuti peab sööklas kaasas olema õpilaspilet, et oma isikut tõendada. Koolisöökla teemana on koolielu kontekstis oluline, see puudutab ja seob õpilasi. 


\section{Põrand on keemia ja füüsika kodutööd}

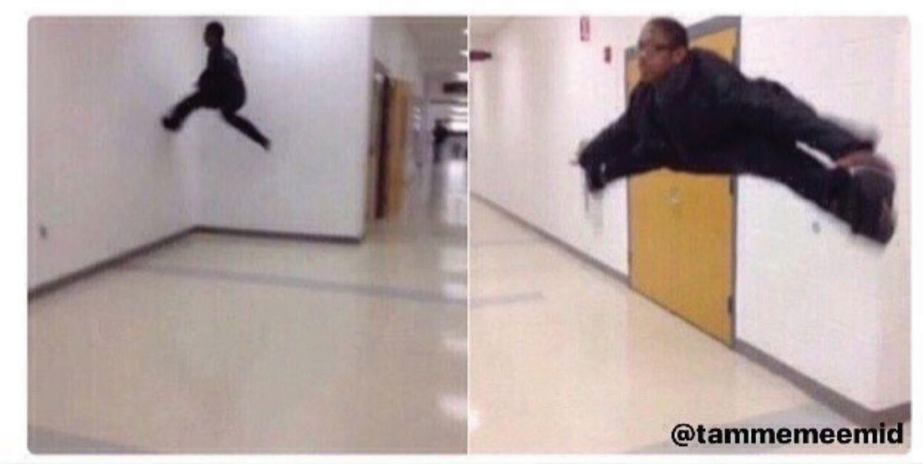

Joonis 8. "Põrand on kodutöö".

Meeme kokku lugedes selgub, et koolielu rutiinidega seotud meeme kohtame kõige sagedamini: need on õppimine ja õppimata jätmine, hinded, kodutööd, kontrolltööd ja testid (Lähte meemilehel 44, Karlovas 31 ja Tammes 24 meemi).

Üheks huvitavaks rahvusvahelise levikuga meemitüübi kodustamise näiteks Eesti koolioludesse on "Põrand on laava". Tavaliselt seostub see Eesti kontekstis mingitpidi just õppeainete või õppimisega. Karlova meemis vihjatakse keemiaõpetaja nõudmistele ainetunnis, Tamme omas rasketele kodutöödele. Samad teemad on ülal ka teiste koolide lehtedel, näiteks Treffneri lehel viidatakse rangele ja nõudlikule, kuid isikupärasele kunstiajaloo õpetajale. Karlova koolis esineb sama meemitüüp ka seostatuna valikeksami allkirja andmisega. Žanrisuhete seisukohalt on meem huvitavaks näiteks, kuidas meemi kaasatakse ka niisuguse žanri elemente, nagu seda on mäng.

\section{Õpetajad ja kaasõpilased}

Kooli igapäevaellu kuulub suhtlemine õpetajatega ja kaasõpilastega. Seetõttu on ootuspärane õpetaja asetamine meemitegelaseks, mida juhtub selgelt sagedamini kui kaasõpilased meemides. Kujutamise konkreetsus on nii kooliti kui isikuti väga erinev. Nagu öeldud, kahandasid ühe kooli meemitegijad vanemate palvel õpetajate kui isikute kujutamist oma meemides. Mõnes Lähte kooli meemis on siiski õpetaja täisnimi, Karlova meemis eesnimi. Meemikangelaseks 
ei satu ükskõik missugune õpetaja - Tamme koolis kohtame meemides ajalooõpetajat, Lähte koolis aga geograafia- ja keemiaõpetajat. Kummalgi juhul ei lähtu meemide kaudu esile tõstetud olukorrad õppeainest, vaid õpilaste-õpetaja vahelistest suhetest.

Inspiratsiooni meemiks võib anda mõni õpetaja poolt sageli korratav fraas või parasiitsõna. Näiteks nii Karlova kui ka Lähte kooli ainestikus kohtame väljendile "Laengud peale!" üles ehitatud meemi. Kooliga mitteseotud inimene satub kergesti tõlgendusraskustesse, ent Karlova meemis asetatakse väljend konteksti: tegu on keemiaõpetaja sagedase väljendiga. Erinevalt meemide puhul tavapärasest väljendi kontekstide väänamisest ja tähenduse nihestamisest on siin alles jäetud meemi verbaalse osa otsene tähendus: keemiatunnis tuleb elektrilaengud indeksina keemilise aine sümboli peale kirjutada. Ilmekaks nüansiks on asjaolu, et sama keemiaõpetaja annab tunde mõlemas koolis. Karlova meemide hulgas leidub kolm meemi, kus kajastatakse keemiaõpetaja kõnepruuki. Õpetaja kaks väljendit: "Rahu!" ja "Latatarakesed" on asetatud Tartu linna kaardile: üks Rahu tänavale ("Kus õpetaja tahaks, et me oleme"; õpilaste arvates võiksid nad olla Latata tänaval Boksburgis LAVis). Meemis sisaldub annus enesekriitilisust: õpilased ajavad juttu, kui peaksid hoopis vaikides tundi kuulama.
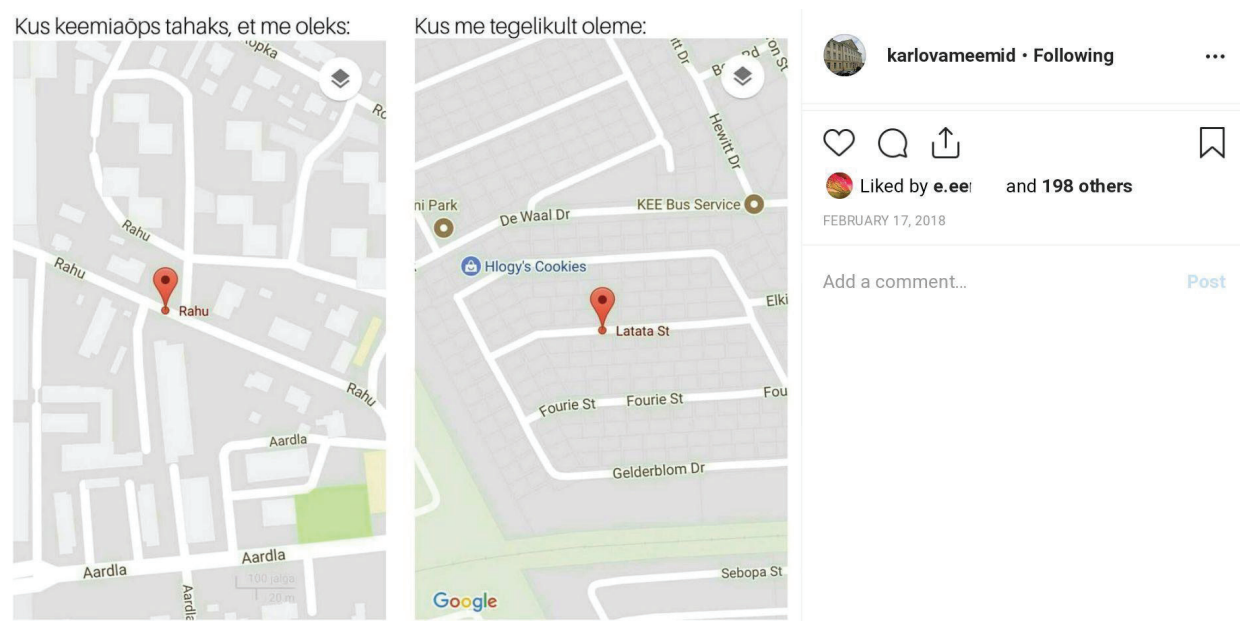

Joonis 9. "Karlova latatarakesed". 
Näiline pinge või kriitika ei tähenda kaugeltki, nagu seataks kahtluse alla õpetaja autoriteet. Intervjuust meemitegijatega saime muuhulgas teada, et keemiaõpetaja on üks nende lemmikõpetajaid, kelle tore kõnepruuk tegelikult meeldib õpilastele. Niisiis, kui meemi naljateravik on suunatud õpetaja kui isiku poole, on meem sageli omamoodi tunnustus - õpetaja isiksus on sedavõrd värvikas, et temast on lugu jutustada (kõnealuses kontekstis on lugu asetatud meemi vormi). Nagu huumori toimimisele omane, varieerub ka meemihuumor laial skaalal. Meemide üheks võtteks on võimendada, asjaolusid rõhutatult (ja liialdatult) esile tuua, see ei tähenda tingimata halvakspanu; vaimukad seosed ja assotsiatsioonid kuuluvad meemide juurde. Naljategemine on pigem õpetajate olemasolu tunnustamine kui rünnak. Võrdluse saab tuua sellisest rahvaluuležanrist nagu naljand. Rahvanaljadele on omane, et sotsiaalne "meie"-teadvus töötab alt üles, samas on sotsiaalne lõige üks põhilõikeid, mille alusel rahvanali oma "meie"/"nemad"-suhteid korrastab (Krikmann 2005: 68-69). Täiskasvanute autoriteetsuse, nende väärtushinnangute ja hindamiskriteeriumite üle naljaviskamine on lääne ühiskondade lasterühmades laialt levinud (Corsaro 2009: 305-306; Kalmre 2005: 167). Nagu teemadegi puhul, saab ka isikute puhul öelda, et meemides kujutatakse vaid persoone, kes meemide vaatajatele korda lähevad, neis tundeid ja seoseid esile kutsuvad. Õpetajad on kahtlemata õpilaste elus tähelepanuväärsed ja neid mõjutavad inimesed.

Muidugi on õpetajate üle naljaheitmise, hüüdnimede leiutamise, lugude jutustamise puhul tegu traditsiooniga, mis ulatub tõenäoliselt kooli kui sellise algusaegadesse. Sellest on juttu nii õpetajate kui ka õpilaste mälestustes. Arvatavasti on igal kunagisel koolinoorel võimalik siia lisada näiteid ka internetieelsest ajastust.

Kaasõpilased meemides on eelkõige kõrvaltegelaste rollis, mõnikord tuleb esile nooremate ja vanemate õpilaste vastandust. Mõnedes seostes kohtame meemides mina-vaadet või õpilaste kui grupi enesekriitikat, näiteks paraku sageli tekkivat olukorda, mil aeg on käes, ent ettevalmistused tegemata meemis "Kui lükkad kõik vastamata tööd edasi veerandi viimasele nädalale"; samuti on meemide kaudu kajastatud terve galerii põhjendusi puudumistele ja hilinemistele või kooli vältimisele, muuhulgas meem "Sa ei saa tundi minna, kui jääd kooli ees auto alla".

\section{Konkreetsed koolieluga haakuvad juhtumid meemides}

Nagu öeldud, on meemides tähelepanu all eelkõige kooli igapäevaelu detailid ja suhted. Ka mõningad koolis või selle ümbruses toimunud sündmused leiavad meemides läbitöötamist. Karlova meemide hulgas on selliseks välgutabamus 


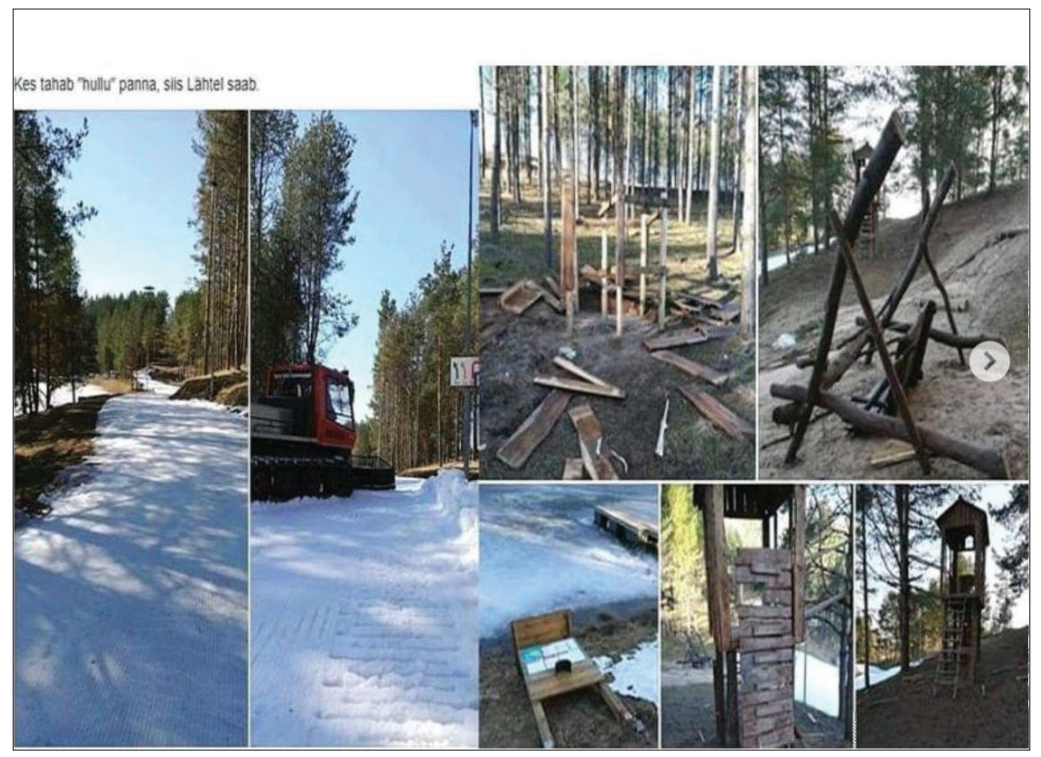

Joonis 10. Vandaalitsemine Lähtel.

kooliõuel kasvavasse tammepuusse 2016. aasta sügisel otse tundide ajal. Lähte meemitegijad kajastasid oma vahenditega ebameeldivat sündmust kohalikus puhkekohas, mis sattus vandaalitsemise ohvriks, kuid kus lõhkujad kiirelt tuvastati ja vastutusele võeti.

2016. aasta piksekärgatus jõudis kahte Karlova meemi. Meemi aluseks seati sündmuse kajastus uudisteportaalis ning täiendati seda omapoolse kommentaariga: "Kui loodusel hakkab Karlova koolist kahju ja otsustab veits feimi anda." Emotsionaalsed vastused, mis järgnesid, lubavad arvata, et õpilased tunnetasid olukorra erandlikkust ja tegelikult ka tõsidust.

Lähtel lõhuti ühel ööl avalikult kasutatava puhkekoha pingid ja infotahvlid. Intsident vormistati meemiks, kus purustused on pildil näha, kommenteeriv tekst on sarkastiline kokkuvõte: "Kes tahab "hullu" panna, siis Lähtel saab" (137 laiki).

\section{Kokkuvõtteks}

Meemide vaatamine ja jagamine on üha rohkemate noorte igapäevase tegutsemise osa. Meemide tegemine eeldab juba ilmset kavatsuslikkust ennast valitud valdkonnas (meemivormis) nähtavaks teha. Postituste jälgimine spetsiaalsetel 
koolide meemilehtedel ning intervjuud meemiloojatega näitavad, et noored väärtustavad vastavaid meeme kui koolielu kajastajaid. Tähenduslik ei ole üksnes meemides väljendatud sündmuste ja olekute tasand, kroonika. Oluline on, et koolielule keskendatud meemid peegeldavad tegijate tahtel ka suhteid ja väärtusi, mis tekitavad kasutajates äratundmist ja vastukaja. Meemid võimaldavad esile tuua antud kogukonna meeldimisi ja mittemeeldimisi; nagu folkloor üldisemalt, meemid nii kajastavad kui ka kujundavad suhtumist. Meemid on tänapäeval nähtavasti ootuspärane viis suhtluses lakooniliselt ja tabavalt edastada kontsentreeritud kujul suurt hulka informatsiooni korraga. Igas meemis on palju informatsiooni - meemi tegema ja levitama ajendanud olukord või seisund, intertekstuaalsed elemendid ja vihjed ning meemikogukonna tõlgendus(ed). Nagu tõendasid eeltoodud näited, rakendavad koolinoored meemidega tegeledes kultuurilist teadmist, meemikoodi, mida täiskasvanud ei pruugi mõista ja mis ei tarvitse täiskasvanute vaateulatusesse sattuda. Samuti ei saa neist meemidest lõpuni aru teiste koolide õpilased, neid meeme esitatakse kui oma koolielu kajastust ning selles tähenduses osaletakse oma kooli tunde, "meie kooli" identiteedi loomises ja hoidmises.

Õpilaste omaloodud koolimeemide lehtedele postitatu toel on näha, kuidas internetisuhtlus ja internetifolkloori jagamine kuuluvad koolinoorte argipäeva ning peegeldavad üleskerkivaid eetilisi ja muid konflikte, aga ka lihtsalt tähelepanekuid ja reaktsioone ümbritseva elu asjaoludele. Ühe meemi käibeloleku aeg on lühike, meemiliiklus on tihe ja kiire, koolimeemide saatuseks on pakkuda sünkroonset, mitte retrospektiivset vaadet koolielus kogetule. Sellegipoolest kuuluvad meemid folkloorse kontsentreeritud väikežanrina niisuguse internetifolkloori alale, mis on kaasatud tähendusloomesse.

\section{Kommentaarid}

1 Artikli valmimist toetasid Eesti Haridus- ja Teadusministeerium (IUT 22-5 "Folkloori usundilised ja narratiivsed aspektid" ja IUT 22-4 "Folkloor kultuurilise kommunikatsiooni protsessis: ideoloogiad ja kogukonnad") ning Euroopa Liit Euroopa Regionaalarengu Fondi kaudu (Eesti-uuringute Tippkeskus).

2 Kasutaja Funqi küsimusest: "Miks Flying Kittyt ei kutsunud? ta kõige kuulsam eesti meemer :)" hargneb lõim 18 vastusega. Samas kommentaaride voos viidatakse ka "Põlva meemide" headusele; samuti leidub päris sõnakat kriitikat klipis nähtud meemide tehnilisele teostusele (vt Kes teevad meeme? 2018).

3 Käesoleva artikli eeltretsenseerimise protsessis andis subkultuuriga seotud eelretsensent artikli autoritele väga olulise vihje: "Peavoolu jõuavad vaid lahjad koopiad ja fragmendid tegelikest tähendustest."

4 Pärimusrühmade moodustumise eripäradest internetis vt Pilt 2014. 
${ }^{5}$ Dank memes kui uurimisobjekt on subkultuuri mittekuuluvale uurijale suhteliselt võimatu missioon. Kui dank meemi omadusena tähendab irooniliselt mõeldud lahedat, siis mittelahe ehk kole meem on just oma iroonilisuse tõttu lahe, laheduse kvaliteet ja iroonia vahetavad mitu korda kohti ja väänduvad teineteiseks, muutudes meemi kui suhtluskeele mittevaldajale hoomamatuks. Tõlgendusabi pakub taas kasutajaskonna enda poolt sisuga täidetav keskkond Know Your Meme, kus on iseloomustatud ka koledate meemide alaliiki (vt https://knowyourmeme.com/memes/dank-memes).

6 Stardipaketi meem on väga produktiivne meemiformaat, mida täidetakse mitmete elualade naljatleva, enamasti liialdava sisuga. Stardipakettide kui selliste meemistamine on otseses iroonilises dialoogis kaubanduses ja muudeski eluvaldkondades pakutavate komplektidega, millegi mitmekaupa peale surumise strateegiatega, ürituste kampaanialisusega. Eesti sotsiaalmeedias levib nii ingliskeelseid stardipaketimeeme (näiteks the Crazy Cat Lady Starter Kit, mis kujutab pappkarbitäit kassipoegi kümnekonna loomakesega) kui ka tõlgitud ja täiesti originaalseid, kohalikus kultuuris loodud komplekte.

\section{Allikad}

Kes teevad meeme? Interneti superstaarid. Delfi TV videointervjuu eesti meemiloojatega. Avaldatud 24. X 2018 (https://www.youtube.com/watch? $\mathrm{v}=\mathrm{rnwmNr} 3 \mathrm{laEg} \&$ index $=2 \&$ lis $\mathrm{t}=\mathrm{LLUvWUDwQNwmVncWosLZkMBw \& t=0 \textrm {s } \& f b c l i d = I w A R 0 J L L S 4 J S f g e t b X f y o l F g b a}$ aFpMvuD8-uMNwZ40mu0hKVh4erIZuwMq9E - 10. juuli 2019).

Mata eksam 2018 = "Laseme üheskoos mata eksami üle" (https://www.facebook.com/ events/219102992024796/?active_tab=discussion - 10. juuli 2019).

\section{Kirjandus}

Allaste, Airi-Alina (koost \& toim) 2013. Subkultuurid. Elustiilide uurimused. Tallinn: Tallinna Ülikooli Kirjastus.

Börzsei, Linda K. 2013. Makes a meme instead: A concise history of internet memes. New Media Magazine: Digital Visual Culture 7, lk 152-193 (http://works.bepress.com/ linda_borzsei/2/ - 10. juuli 2019). [Online.]

Corsaro, William A. 2009. Peer Culture. Qvortrup, Jens \& Corsaro, William A. \& Honig, Michael-Sebastian (toim). The Palgrave handbook of childhood studies. Basingstoke \& New York: Palgrave MacMillan, lk 301-315.

Davison, Patrick 2012. The Language of Internet Memes. Mandiberg, Michael (toim). The social media reader. New York \& London: New York University Press, lk 120-134.

Goldstein, Rebecca A. 2006. Oh Puhleeze! Learning Youth Culture. Steinberg, Shirley \& Parmas, Priya \& Richard, Birgit (toim). Contemporary youth culture: An international encyclopedia. Westport: Greenwood Press, lk 3-10.

Hine, Christine 2015. Ethnography for the internet: Embedded, embodied and everyday. London: Bloomsbury. 
Howard, Robert Glenn 2008. Electronic Hybridity: The Persistent Processes of the Vernacular Web. Journal of American Folklore 121, lk 192-218 (doi: 10.2307/20487596).

Howard, Robert Glenn 2012. How counterculture helped put the "vernacular" in vernacular webs. Blank, Trevor J. (toim). Folk Culture in the Digital Age: The Emergent Dynamics of Human Interaction. Logan: Utah State University Press, lk 25-45 (doi: 10.7330/9780874218909.c01).

Howard, Robert Glenn 2013. Vernacular Authority. Critically Engaging “Tradition". Blank, Trevor J. \& Howard, Robert G. (toim). Tradition in the Twenty-First Century. Locating the Role of the Past in the Present. Logan: Utah State University Press, lk 72-99 (doi: 10.7330/9780874218992.c03).

Honko, Lauri 1998. Folklooriprotsess. Mäetagused 6, lk 56-84 (doi: 10.7592/MT1998.06. honko).

Kalmre, Eda 2005. Laste- ja noortepärimus. Metsvahi, Merili \& Valk, Ülo (toim). Regivärsist netinaljadeni. Sissejuhatus rahvaluulesse. Tallinn: Koolibri, lk 163-179.

Kalmre, Eda 2015. Self-created love strories in girls' romantic culture: history and evolution. Enguix Grau, Begonya \& Roca, Jordi (toim). Rethinking Romantic Love: Discussions, Imaginaries and Practices. Newcastle upon Tyne: Cambridge Scholars Publishing, lk 241-270.

Kaplan, Merrill 2013. Curation and Tradition on Web 2.0. Blank, Trevor J.; Howard, Robert G. (toim). Tradition in the Twenty-First Century. Locating the Role of the Past in the Present. Logan: Utah State University Press, lk 123-148 (doi: 10.7330/9780874218992. c05).

Krikmann, Arvo 2005. Naljandid ja anekdoodid. Metsvahi, Merili \& Valk, Ülo (koost). Regivärsist netinaljadeni. Sissejuhatus rahvaluulesse. Tallinn: Koolibri, lk 63-77.

Laineste, Liisi \& Voolaid, Piret 2016. Laughing across borders: Intertextuality of Internet memes. European Journal of Humour Research 4 (4), lk 26-49.

Milner, Ryan M. 2016. The World Made Meme: Public Conversations and Participatory Media. Cambridge: The MIT Press (doi: 10.7551/mitpress/9780262034999.001.0001).

Mitchell, Liam 2013. "Because none of us are as cruel as all of us": Anonymity and Subjectivation. Ctheory.net (journal of theory, technology, and culture) (http://ctheory.net/ ctheory_wp/because-none-of-us-are-as-cruel-as-all-of-us-anonymity-and-subjectivation/ 10. juuli 2019).

McNeill, Lynne S. 2009. The End of the Internet: A Folk Response to the Provision of Infinite Choice. Blank, Trevor J. (toim). Folklore and the internet: vernacular expression in a digital world. Logan: Utah State University Press, lk 80-97 (doi: 10.2307/j.ctt4cgrx5.7).

Pilt, Maili 2014. Kohtumispaik internetifoorum. Sissevaateid virtuaalrühma kollektiivsusesse. Kõiva, Mare (koost \& toim). Maailm ja multitasking. Tänapäeva folkloorist 10. Tartu: EKM Teaduskirjastus, lk 23-50 (doi: 10.7592/TF10.foorum).

Shifman, Limor 2013. Memes in Digital Culture. The MIT Press Essential Knowledge Series. Cambridge: MIT Press. 
Thornton, Sarah 1995. Club cultures: music, media and subcultural capital. Cambridge: Polity Press.

Tucker, Elizabeth 2008. Children's Folklore: A Handbook. Westport (Conn): Greenwood Press.

Valk, Ülo 2005. Mis on rahvaluule? Valk, Ülo \& Metsvahi, Merili (koost). Regivärsist netinaljadeni. Sissejuhatus rahvaluulesse. Tallinn: Koolibri, lk 9-12.

Virtanen, Leea 1978. Children's Lore. Studia Fennica 22. Helsinki: Suomalaisen Kirjallisuuden Seura.

Voolaid, Piret 2014. Varateismeliste identiteet ja väärtused Facebooki ahelpostitustes. Kõiva, Mare (koost \& toim). Maailm ja multitasking. Tänapäeva folkloorist 10. Tartu: EKM Teaduskirjastus, lk 49-76 (doi: 10.7592/TF10.facebook).

\title{
Summary
}

\section{Reflecting school life in the self-made memes of primary school students in the Tartu region}

\author{
Mare Kalda \\ Senior Research Fellow \\ Department of Folkloristics, Estonian Literary Museum \\ mare.kalda@folklore.ee \\ Astrid Tuisk \\ Research Fellow \\ Estonian Folklore Archives, Estonian Literary Museum \\ astrid.tuisk@folklore.ee
}

Keywords: children's culture, children's folklore, internet memes, virtual culture, youth culture

Internet memes represent a new vernacular genre, items of which are created and also distributed digitally. Every day, ever new information keeps flowing through the feeds of social media sites. Internet memes, unlike traditional folklore, are not meant to be conveyed from generation to generation, and rarely would one expect a recurrence of a meme that has already been seen and passed forward. New memes are being created constantly, representing every conceivable aspect of physical as well as virtual reality. The external world is represented through a seemingly anything-goes game of combining shapes and forms. Already in the current stage of development of the genre, we can notice that memes correspond to their users' subcultural and other group-related preferences. Age-group specific meme use is also discernible.

This paper focuses on the meme repertoire of schoolchildren in the Tartu region, which is published on special Facebook or Instagram pages. The empirical work consisted in observing the meme sites and interviewing those generating the memes. School memes 
are presented as depiction of the life in a particular school and used for generating a feeling of belonging within that school.

By memeing, schoolchildren apply a certain kind of cultural knowledge, a memetic code, which is not necessarily accessible to adults - indeed, they might not even have encountered it. William Corsaro characterises peer group culture with keywords such as autonomy, control, conflict, and differentiation; the challenge is to make fun of the authority of adults. In school memes, we are witnessing not only a peer group counterculture, but also an endeavour by the group to create a certain distinct world of its own. The novel and youthful memetic form suits well for this project. 